\title{
Conventional Displays: Evidence for Socially Mediated Costs of Threat Displays in a Lizard
}

\author{
Peter L. Hurd*
}

Section of Integrative Biology, University of Texas

\begin{abstract}
Threat displays are used to settle the vast majority of contests between green anoles (Anolis carolinensis). While these displays have been the subject of a number of studies, very little is understood about the information they convey. Theoretical models divide displays into several types of signals, based on the mechanism that stabilizes their use: 1) performance signals, 2) handicapping signals, or 3) conventional displays. The existence of performance displays has excellent empirical support, as do models of their use. Handicapped signalling models, especially those relating to mate-choice, have been highly influential, though little evidence suggests that threat displays are, in fact, handicapping. Most threat displays appear to be conventional, but little empirical work documents conventional signalling systems. This study investigated the use of headbob, pushup, and lateral compression displays, and concluded that headbob cadence, a discrete signal with three alternative rhythms, is a conventional display indicating impending escalation. Pushups and lateral compression displays appear not to be handicaps, since neither indicates impending escalation, and they do not correlate with fighting ability or condition. Aggr. Behav. 30:326-341, 2004. (C) 2004 Wiley-Liss, Inc.
\end{abstract}

Keywords: threat display; lizard; game theory; Anolis carolinensis

\section{INTRODUCTION}

Most agonistic interactions between conspecifics are resolved through the use of displays, rather than physical combat [Alcock, 1998; Riechert, 1998]. The factors determining which display is chosen from a repertoire of threats, and the response to it, remain poorly understood. There is a readily apparent benefit to using the display that is most likely to elicit withdrawal or subordinance from the opponent [Dawkins and Krebs, 1978; Krebs and Dawkins, 1984]. If all individuals were to "bluff" in such a manner, there would be no variation in display use, and, therefore, no communication [Caryl, 1979]. In order to have evolutionarily stable variation in signal use, a cost must negate the benefits of escalated signals under some circumstances. The sources of counter-balancing costs to more escalated threats are less obvious than are the benefits. The question central to this continuing problem is: how can reliable signalling exist in the face of such readily apparent selection for bluffing?

*Correspondence to: Peter L. Hurd, Department of Psychology, University of Alberta, Edmonton, Alberta T6G 2E9 Canada. E-mail: phurd@ualberta.ca

Received 20 May 2002; amended version accepted 13 December 2003

Published online in Wiley InterScience (www.interscience.wiley.com). DOI: 10.1002/ab.20020 
Game theoretical models have addressed the maintenance of reliable communication [Adams and Mesterton-Gibbons, 1995; Caryl, 1979; Enquist, 1985; Grafen, 1990; Johnstone, 1997, 1998; Kim, 1995; Maynard Smith, 1974]. Communication during aggressive interactions poses a particular problem, since some degree of common interest must exist for communication to take place, while participants in such interactions clearly have opposing interests. One of the first realistic models of agonistic communication is the sequential assessment game [Enquist and Leimar, 1983, 1987; Leimar and Enquist, 1984]. This is a model of aggressive interaction, with considerable empirical support [Brick, 1999; Englund and Olsson, 1990; Englund and Otto, 1991; Enquist and Jakobsson, 1986; Enquist et al., 1987, 1990; Keeley and Grant, 1993; Koops and Grant, 1993; Leimar et al., 1991]. Signal reliability is maintained in the sequential assessment game by assuming that the signals are constrained to produce reliable, though imprecise, information. The model provides a good prediction of behaviour when signals are constrained to provide information about traits, such as size asymmetries. In this paper, signals that are constrained in this way will be referred to as performance signals [Hurd, 1997], since differences in the ability to perform these signals determines their use. Examples include the lateral displays of many fish [e.g. Enquist and Jakobsson, 1986], or the pitch of calls in many species of frog [e.g. Gerhardt, 1994], both unbluffable signals indicating size and fighting ability. Certainly, not all aggressive signals are constrained in such a manner. If signal use is not constrained by ability to perform the signal, then variation in signal use may be due to variation in the choice of signals; such signals are strategic signals [Johnstone, 1998]. Theoretical work identifies two types of strategic signals: handicaps and conventional signals. Handicap displays either place the signaller in a position vulnerable to attack, or impose some wasteful cost, effectively weakening the signaller [Johnstone, 1997]. Table I summarizes the three signal types.

The evidence in support of handicaps is more theoretical than empirical, especially in the case of threat displays. Few threat displays appear to work as the handicap hypothesis predicts [Hurd and Enquist, 2001]. The earliest rigorous game theoretical model of strategic threat display use was a model of conventional threat displays [Enquist, 1985]. This model is stabilized by costs derived entirely from the receiver's reaction to signals, which are costless to produce (or at least, in which alternative signals do not differ significantly in their costs of production), and do not differentially expose signallers to counter-attack [Enquist et al., 1998; Hurd, 1997; Hurd and Enquist, 1998].

To test the handicap hypothesis empirically we must examine the information content of these signals as a function of their type. This paper investigates threat display use by Green anoles (Anolis carolinensis) for information about impending escalation, and classifies these signals by probable type (conventional or handicapped).

Green anoles employ a wide repertoire of displays during agonistic interactions [see ethogram in Greenberg, 1977]. An obvious candidate conventional signal (headbob type) and

Table I. Signal Types

\begin{tabular}{lcc}
\hline Signal Type & $\begin{array}{c}\text { Signal Constrained by } \\
\text { Ability to Perform? }\end{array}$ & $\begin{array}{c}\text { Source of } \\
\text { Stabilizing Cost }\end{array}$ \\
\hline $\begin{array}{l}\text { Performance } \\
\text { Handicap }\end{array}$ & Yes & none \\
Conventional & No (Strategic) & Production \\
\hline
\end{tabular}


two candidate handicap signals (pushups and lateral compression) were investigated. Headbobbing, pushing up, and lateral compression are three of the most striking elements of the Anolis agonistic repertoire. Headbobs and pushups are closely related (every pushup occurs during a headbob); every headbob is either a zero-, two-, or four-legged pushup. It has been suggested that pushup intensity serves as a graded signal of aggressive motivation [Martins, 1993]. Each headbob has one of three distinct rhythms, called types "A," "B," and "C." All individuals perform a variety of headbob and pushup types, but the pushup type has no effect on the rhythm of any given type of headbob [Jenssen et al., 2000]. The proportion of headbob types is known to vary as a function of inter-male distance, with " $\mathrm{C}$ " headbobs used at the longest ranges, and "A" at the closest [DeCourcy and Jenssen, 1994; Jenssen et al., 2000].

Headbob type may be a conventional signal. There is no a priori reason why different rhythms of headbob impose significantly different costs, either in their production or in the degree to which they render the signaller vulnerable to counter-attack. If different individuals are unconstrained in their choice of the three headbob types, and they do not have different inherent costs of production, then they will use conventional signals.

Pushups and lateral compression may be handicap signals. Their variability, zero-, two-, or four-legged pushups, lateral compression vs. relaxed torso, is quantitative and directional. It is plausible that both are energetically costly to perform, and more costly for more exaggerated forms. Lateral compression is thought to hinder breathing, thereby handicapping the performing lizard. For example, a specimen of the side-blotched lizards, Uta stanisburiana, fatigued by running on a treadmill to half it's pre-determined endurance capacity, subsequently performed fewer laterally compressed pushups, but did not perform fewer pushups when not laterally compressed [Brandt, 2003]. Signals that bear a significant cost are obvious candidates for handicapped signals, and their use can be expected to correlate with condition.

This study will investigate headbob type, pushup type, and use of lateral compression for association with impending escalation, fighting ability, and condition.

\section{METHODS}

Twenty-seven adult male A. carolinensis, seven caught on or around the University of Texas campus, and twenty purchased from commercial suppliers, were tested. Each lizard was tested in a standard five gallon aquarium $(40 \times 20 \times 25 \mathrm{~cm}, 1 \times \mathrm{w} \times \mathrm{h})$ which served as its home cage for at least 12 days before testing. All lizards were held in social isolation for at least 24 days prior to testing.

Three of the home cage walls were obscured by taping white paper over the outside of the walls. This prevented lizards from seeing each other, and effectively eliminated reflected images inside the cages. The fourth wall was obscured with a white plastic partition, which was removed during mirror presentations. Each tank contained a wooden dowelling perch placed diagonally across the tank running from top left at the back of the tank to bottom right. This prevented any bias between individuals with respect to which eye lizards would most likely have towards the mirror when at the top of the perch facing the mirror. Which eye a lizard sees its opponent with has been shown to influence aggressive behavior [Deckel, 1995].

The testing room was illuminated with UV/B producing fluorescent lights, and one corner of each aquarium was illuminated with an incandescent lamp, both on a $15 \mathrm{~h}: 9 \mathrm{~h}$ light:dark schedule. Air temperatures in the testing room were about $31.5^{\circ} \mathrm{C}$ during the day. Lizards 
were fed calcium-dusted crickets on alternate days. Water was available in shallow bowls containing rocks and misted daily.

At the beginning of each test, the plastic partition was removed to reveal a one-way mirror. Each lizard was filmed through the mirror for five minutes following the first agonistic act. Filming was halted after $15 \mathrm{~min}$. if no agonistic act was seen. Each lizard was filmed eight times. There were four test periods, each consisting of two consecutive days, with five nontest days in between each test period. Three measurements were taken, at the end of each test period, for both mass and snout-vent-length (SVL); the median value was used. Condition was calculated as $\sqrt[3]{\text { mass }} /$ SVL.

The following behaviours were scored from videotape: Lateral Compression, Extended Throat, Post-orbital Eyespot (POES), and Headbobs. All were defined according to Greenberg [1977].

Headbobs were further classified according to rhythm type and pushup type. Headbobs were classified as rhythm type A, B, C, or W (unknown) according to the DAP graphs presented by DeCourcy and Jenssen [1994] (see Fig. 1). Each headbob is also accompanied by some pushup type, scored as either None, PU (a two-legged pushup), or FLPU (a four-legged pushup). Pushups were defined as a displacement of the torso of greater than $1 / 8$ th of a body depth, and started with the initial movement in the headbob.

Two forms of escalation were scored. The first, Charge, was any continuous body movement of at least one body length towards the mirror. The second, Attack, was any physical contact with the mirror (provided the animal was not in contact with the mirror when the partition was raised, in which case attack was not scored unless the animal left the mirror wall, then returned to it).

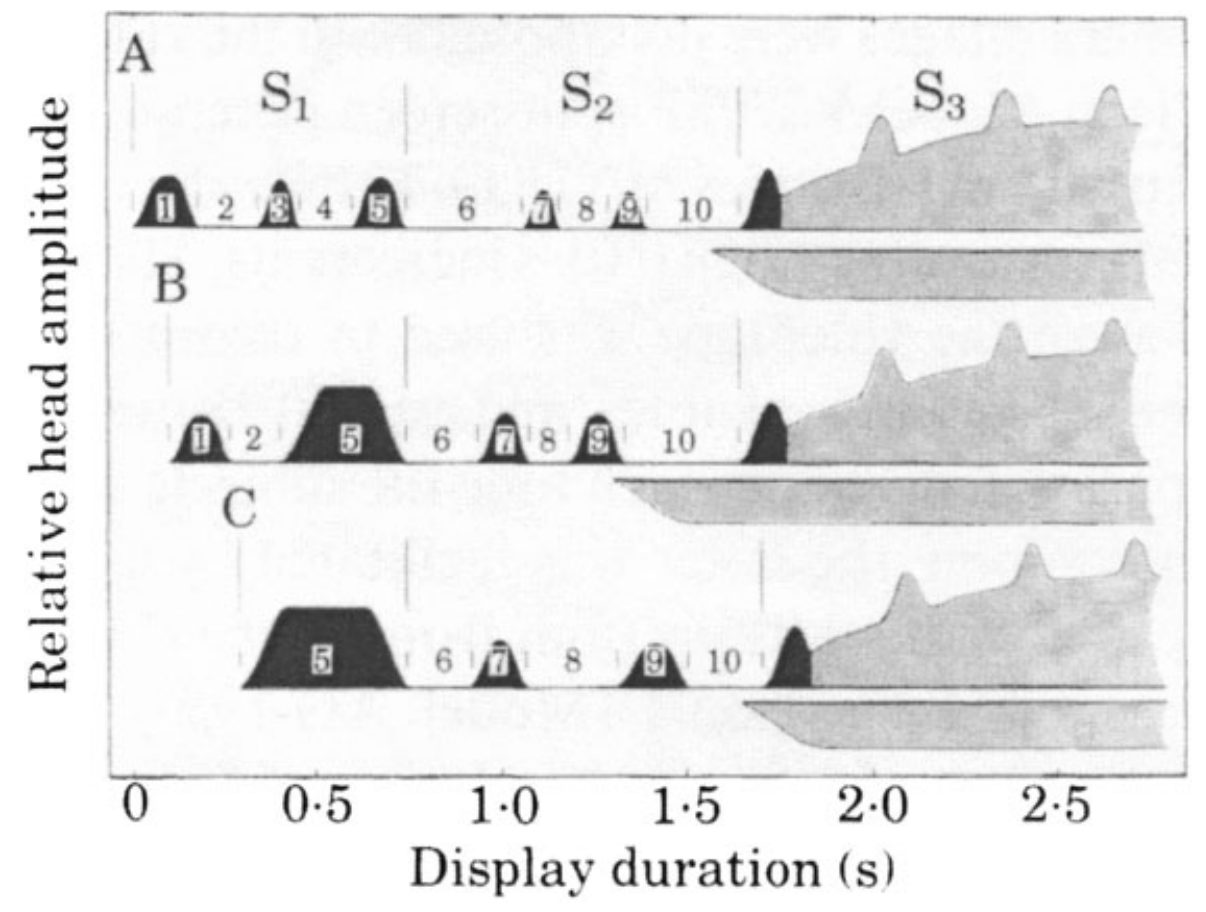

Fig. 1. Display Action Patterns for the three rhythms of headbobs, reproduced from De-Courcy and Jenssen [1994]. 
All statistical analyses (Wilcoxon's signed rank, Log-likelihood ratio, $\chi^{2}$, Pearson's product-moment correlation, Spearman's rank-order correlation) were performed in $\mathrm{R}$ [Ihaka and Gentleman, 1996].

\section{RESULTS}

The lizards responded aggressively to the mirror stimulus in $177(81.9 \%)$ of the 216 tests. One lizard did not show any aggressive behaviour on any of the eight days, one failed to show aggression on five days, two showed no aggression on four days, one showed none on three, three showed none on two, and five showed no aggression on one day. Fourteen lizards showed some level of aggression every day.

Escalation was defined as the first advance or attack made by a lizard. There was no difference between the number of headbobs prior to escalation $(\bar{X}=5.7, N=67)$, and the total number used in trials without escalation $(\bar{X}=6.1, N=110)$, Wilcoxon signed ranks test on all data $(T=3658: 5 ; N=177 ; P=0.94)$. The same result was obtained when using the average number of bobs prior to escalation, and in non-escalated tests, for each lizard $(T=359 ; N=27 ; P=0.93)$.

\section{Headbob Type}

Type $\mathrm{C}$ headbobs were the most common. Of the total 27 lizards, two performed no headbobs, seven performed only type $\mathrm{C}$ headbobs, four performed types $\mathrm{C}$ and $\mathrm{B}$ only, three performed types $\mathrm{C}$ and $\mathrm{A}$ only, and eleven performed all three types. Of the fifteen lizards that performed both $\mathrm{B}$ and $\mathrm{C}$ headbobs, all used more $\mathrm{C}$ than $\mathrm{B}$ (binomial test, $N=15$; $P<0.0001)$. Of the fourteen lizards that performed both $\mathrm{A}$ and $\mathrm{C}$ headbobs, all performed more $\mathrm{C}$ than A (binomial test, $N=14 ; P<0.0001$ ). Type B headbobs were more commonly used than type A headbobs. Of the eleven lizards that used both $\mathrm{A}$ and B type headbobs, ten used more type B than A (binomial test, $N=11 ; P<0.05$ ).

Headbob type predicted impending escalation. Overall, far more headbobs immediately preceding the first charge by a lizard were of types " $\mathrm{A}$ " and " $\mathrm{B}$ " than were all headbobs used in that session leading up to that point $\left(\chi_{2}^{2}=35.4, \mathrm{P}<0.001\right.$, Fig. 2$)$ (all Ws were dropped from the data for this analysis). This result is vulnerable to pseudo-replication, since different lizards contribute to the dataset in varying amounts. Three lizards provided enough data to analyze individually, two of the three used significantly more "A" and "B" headbobs immediately prior to escalation, than in the displays leading up to that point $\left(\mathrm{G}_{\text {yates }}=8.0\right.$; $6.1 ; 0.1 ; \mathrm{p}=0.005 ; 0.01 ; 0.77$ respectively - log likelihood tests used due to small sample sizes). Of the remaining lizards, four used a higher proportion of " $A$ " or " $B$ " headbobs in the period immediately prior to an escalation, than earlier in the experiment. None of the rest of the escalating lizards $(\mathrm{N}=12)$ used any " $\mathrm{A}$ " or " $\mathrm{B}$ " headbobs prior to escalation.

There was also a general tendency towards a higher proportion of " $A$ " and "B" headbobs as the latency to charge decreased $\left(r_{\mathrm{s}}=56 ; N=6 ; p=0.24\right.$, Fig. 3). Overall, a significantly greater proportion of headbobs immediately prior to an advance were of types " $A$ " and " $B$ " than were all headbobs in tests which did not subsequently lead to escalation, $\left(\chi_{2}^{2}=23.2\right.$, $P<0.001$, Fig. 2) (all Ws were dropped). When each lizard was analyzed individually, only one showed a statistically significant effect $\left(\mathrm{G}_{\text {yates }}=4.10 ; \mathrm{p}=0.041\right)$. The overall result cannot be attributed solely to this one individual however, as it accounted for less than $17 \%$ of the analyzed data. 


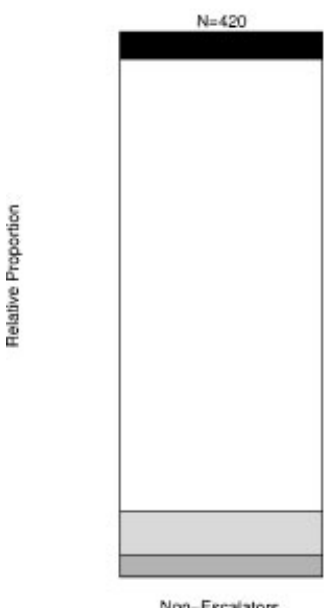

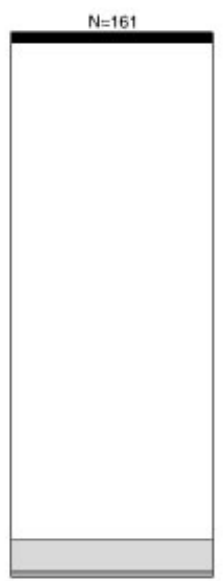

Prior

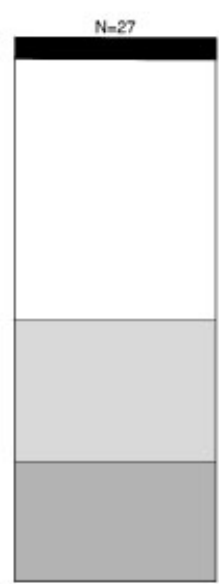

Immediakely Preceoding

Fig. 2. Headbob type as a function of impending escalation. "Non-escalators" includes all headbobs from lizards which neither charged, nor touched the mirror. "Immediately Preceding" is a count of the last headbob used before the first Charge (as long as the interval between headbob and advance was less than 60 seconds). "Prior" is a count of all headbobs used prior to that which immediately preceded the first charge (unless the latency was 60 seconds or more). Significantly more headbobs immediately prior to an advance were of types " $A$ " and " $B$ " than either all preceding headbobs, or all headbobs in contests whichdid not go to escalation.

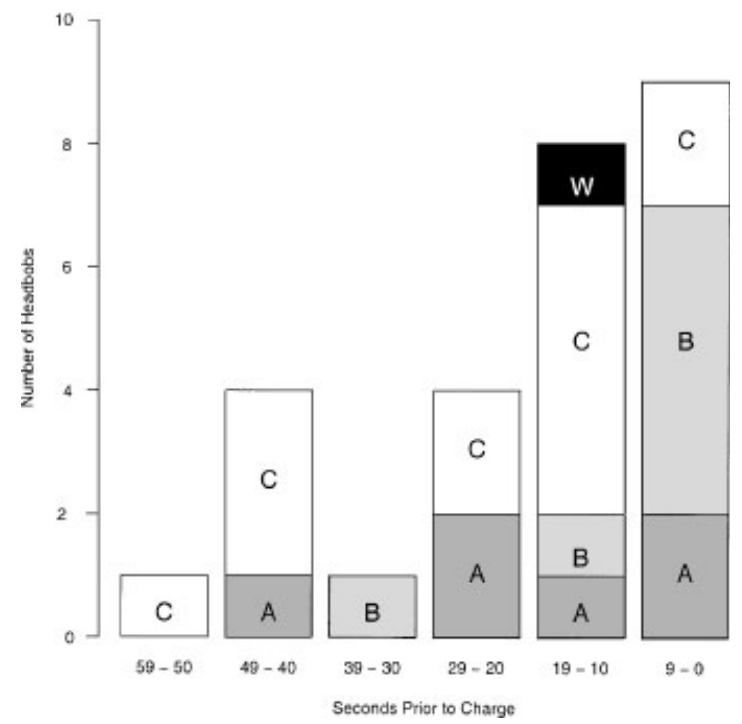

Fig. 3. Headbobs from the "Immediately Preceding" category in Fig. 2, as a function of the latency to the start of the charge. Of the 18 headbobs preceding a charge by more than 60 seconds, 17 were of type $C$, and one of unknown type (W). Note that the proportion of A and B headbobs is higher the shorter the latency.

There was no significant difference in the proportions of headbob types used by lizards which did not escalate, and those used prior to a charge to the mirror, other than the very last one $\left(\chi_{2}^{2}=5.3 ; N S\right.$, Fig. 2$)$. This strongly suggests that it is not the ability to perform the different headbobs that determines their use. 


\section{Pushup Type}

Of the 27 lizards, two lizards performed no pushups, all others performed from one to 107 two or four legged pushups (entire population mean $=26.3$, median $=16$ ). Thirteen lizards performed from one to 20 four-legged pushups.

There was no change in pushup type immediately prior to a charge (all pairwise $\left(\chi_{4}^{2}=6.0\right.$; $P=0.20$; entire matrix $\left(\chi_{4}^{2} ; P=0.12\right.$, Fig. 4$)$ ), or in the proportion of headbobs that were accompanied by pushups (either two or four legged) over time in either escalating, or nonescalating tests (Escalators: $r=0.004 ; N=10 ; P=0.99$; Non-escalators: $r=0.38 ; N=10$; $P=0.28$, Fig. 5a). There was a decrease in the proportion of headbobs accompanied by fourlegged pushups by non-escalators, but not by escalators (Escalators: $\mathrm{r}=0.15 ; N=10$; $P=0.72$; Non-escalators:, $r=-.90 ; N=10 ; P<0.005$, Fig. 5b). This decrease appears due to a sharp decrease in the use of four-legged pushups around the seventh headbob. There was an average of 5.7 headbobs prior to escalation, making it doubtful that four-legged pushups serve as a signal of impending escalation.

\section{Headbob and Pushup Types}

The type of pushup performed was associated with the type of headbob. Far more headbobs of types $\mathrm{A}$ and $\mathrm{B}$ are performed without pushups than are type $\mathrm{C}\left(\chi_{4}^{2}=65\right.$; $\mathrm{p}<0.0005$, Fig. $6, \mathrm{~W}$ headbobs dropped from the analysis). This is in contrast to the idea that pushups are signals of aggressive motivation [Martins, 1993], C headbobs are associated with larger distances between signaller and receiver [DeCourcy and Jenssen, 1994], and indicate a lower probability of impending escalation (present results). Figure 7 shows the association between pushup and headbob types in cases in which the lizard did not escalate, and prior to, and subsequent to, escalation in lizards that did escalate.

Note that pushup intensity and A and B type headbobs are negatively associated in most contexts (statistical analyses presented in Fig. 7). This suggests that pushup intensity signals a property distinct from that signalled by headbob type.
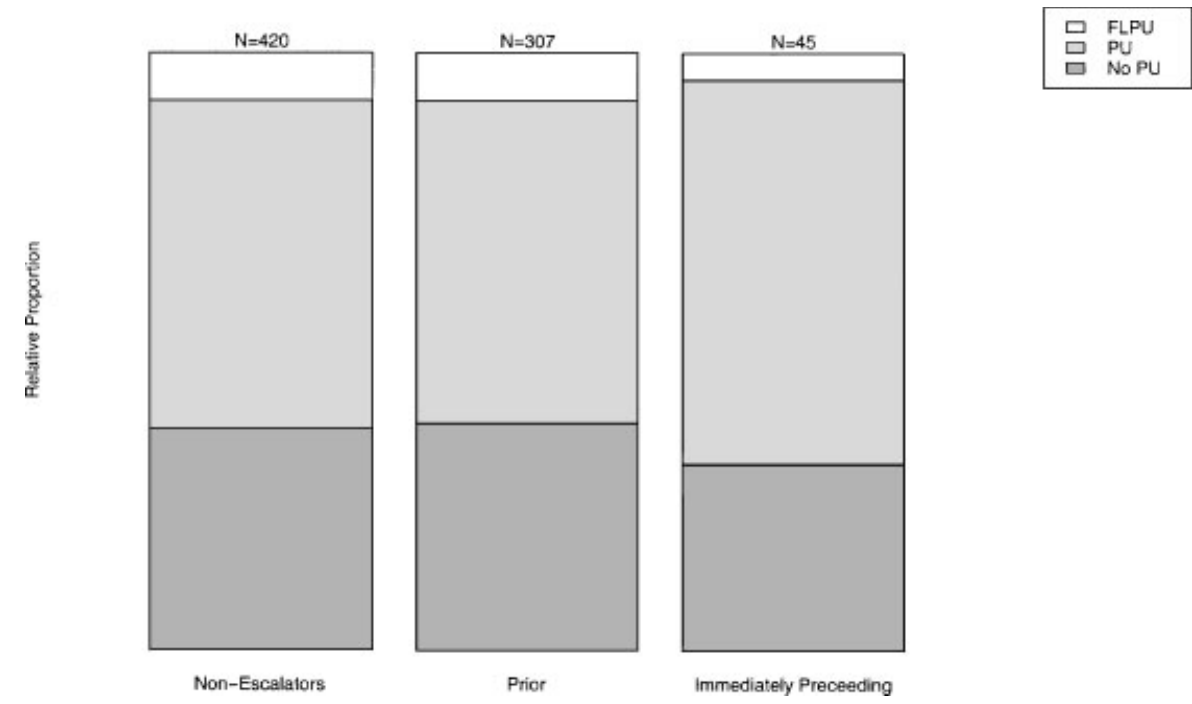

Fig. 4. Pushup type as a function of impending escalation. Pushup type does not appear to signal impending attack. 


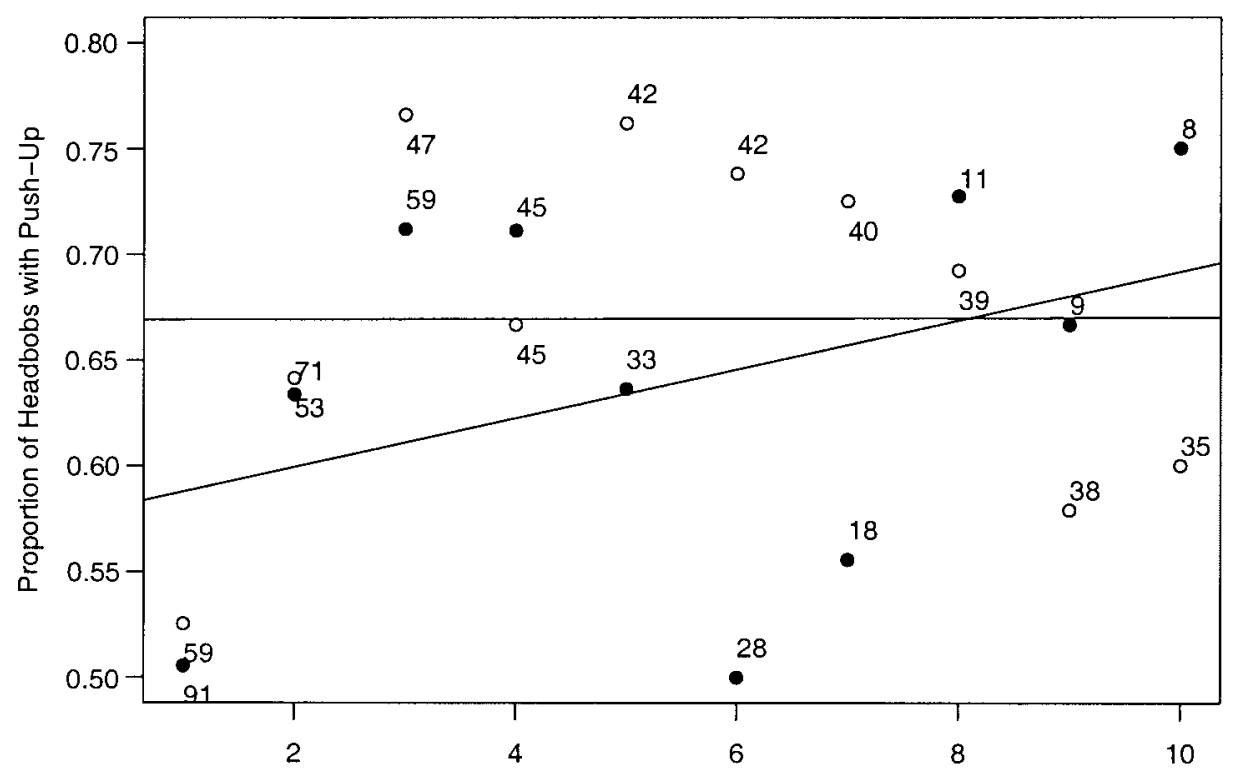

(A)

Headbob Number

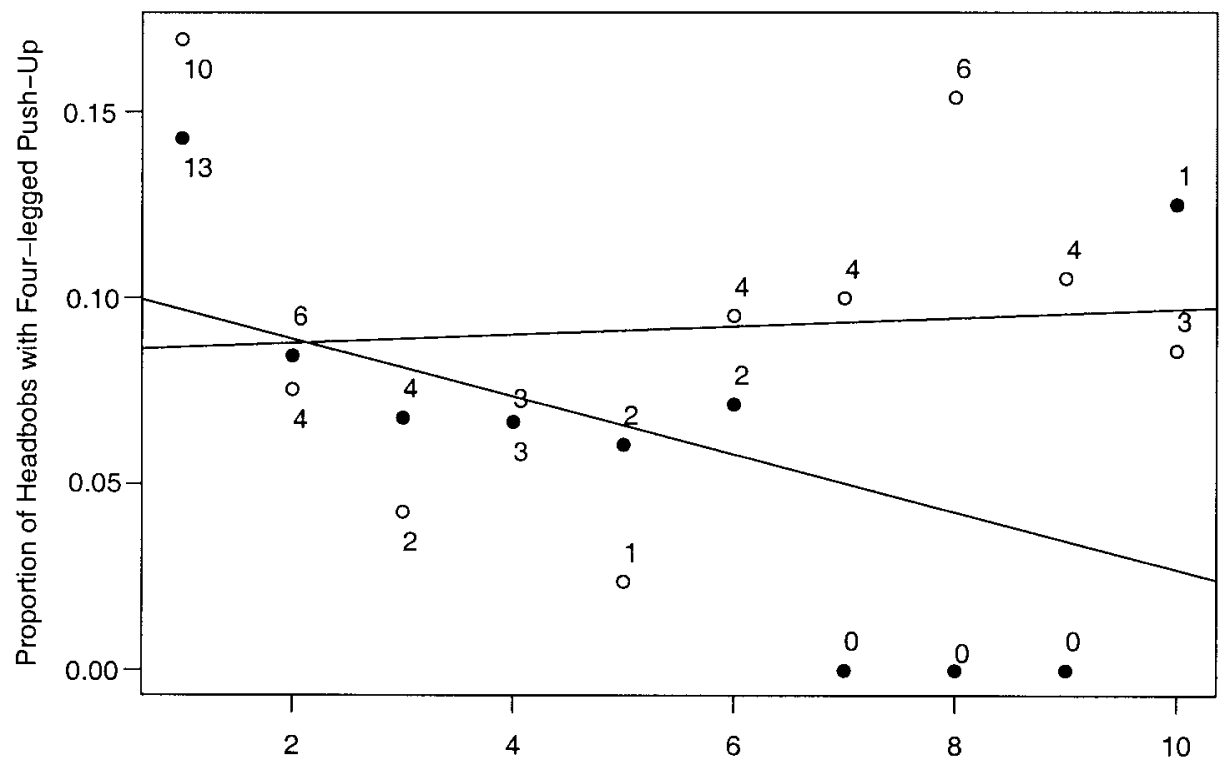

(B)

Headbob Number

Fig. 5a. Proportion of headbobs accompanied by pushups (either two of four legged) for the first ten headbobs. Lizards that escalated to advancing or attacking are shown with open circles, while those that did not escalate are shown with filled circles. Numbers indicate sample sizes for each data point. Neither slope was significantly different from zero.; (b) Change in the proportion of four-legged pushups as a function of eventual escalation. Escalators did not change in the proportion of headbobs over the first eight headbobs, while Non-escalators showed a significant decrease in the proportion of pushups over the first eight headbobs. Sample sizes as in Fig. 7, numbers beside the data points indicate the number of four legged-pushups. 

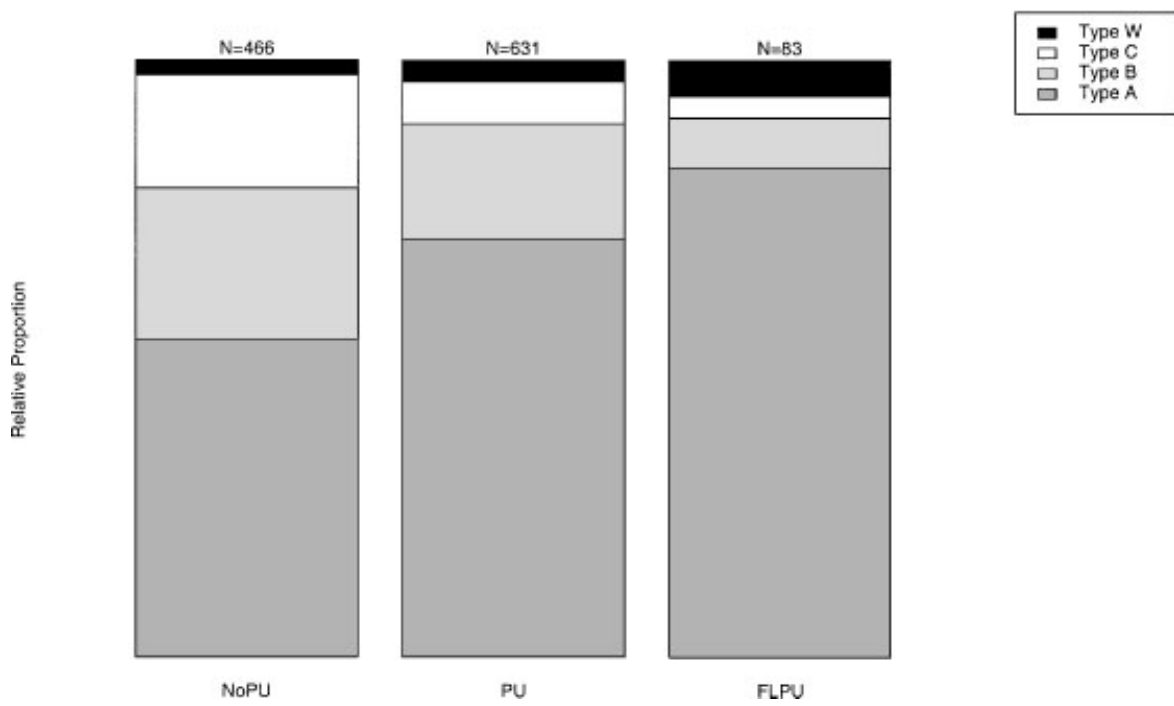

Fig. 6. Association between headbob type (rhythm) and pushup type (number of legs used).
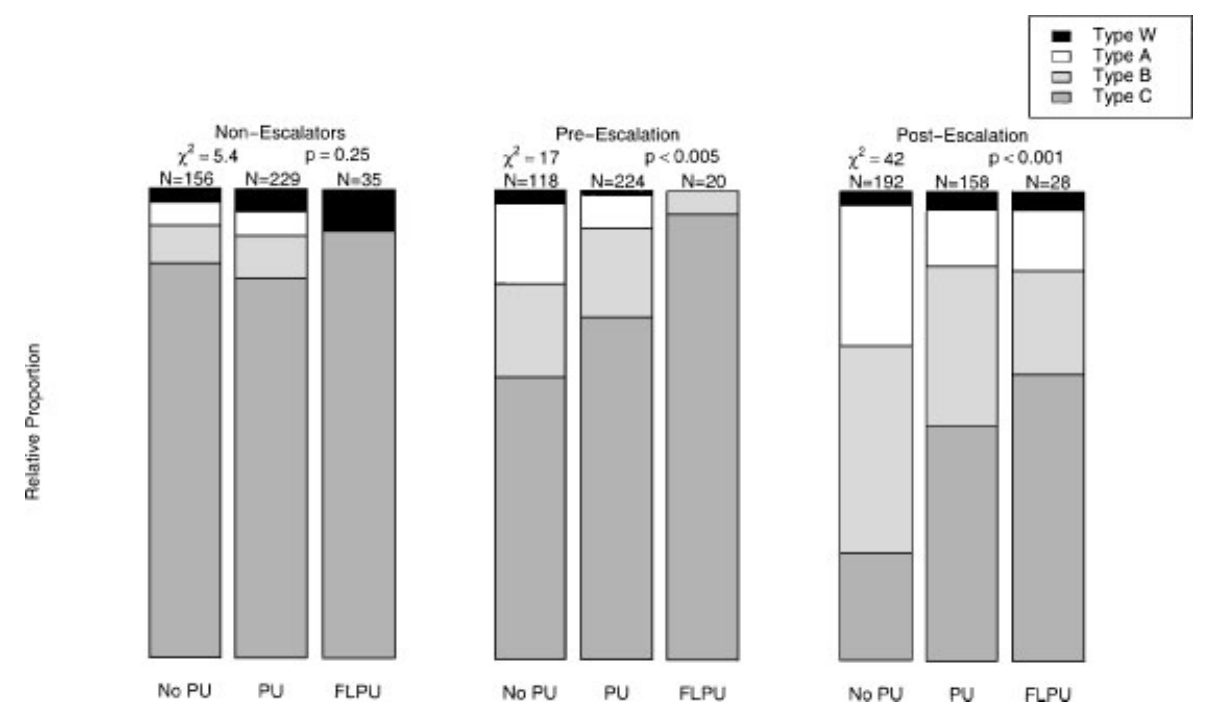

Fig. 7. Non-escalators includes all headbobs from lizards which neither charged, nor touched the mirror. Pre-Escalation is a count of all headbobs used before charging the mirror (or before touching the mirror, if that happened without first having a Charge). Post-Escalation is a count of all headbobs used after a Charge or Attack. All "W"s were dropped from the statistical analyses.

\section{Lateral Compression}

Lateral compression was seen in 140 of 216 tests. The average time spent compressed was 194 seconds (during the 300 second test). Of the 27 lizards, one never exhibited lateral compression, and one showed lateral compression on each two days. Five lizards showed lateral compression on three days, four on four days, two on five days, three on 
Table II. Escalation as a Function of Lateral Compression

\begin{tabular}{lcc}
\hline & $\begin{array}{c}\text { No Lateral } \\
\text { Compression }\end{array}$ & $\begin{array}{c}\text { Lateral } \\
\text { Compression }\end{array}$ \\
\hline No Escalation & 28 & 82 \\
Escalation & 11 & 56 \\
\hline
\end{tabular}

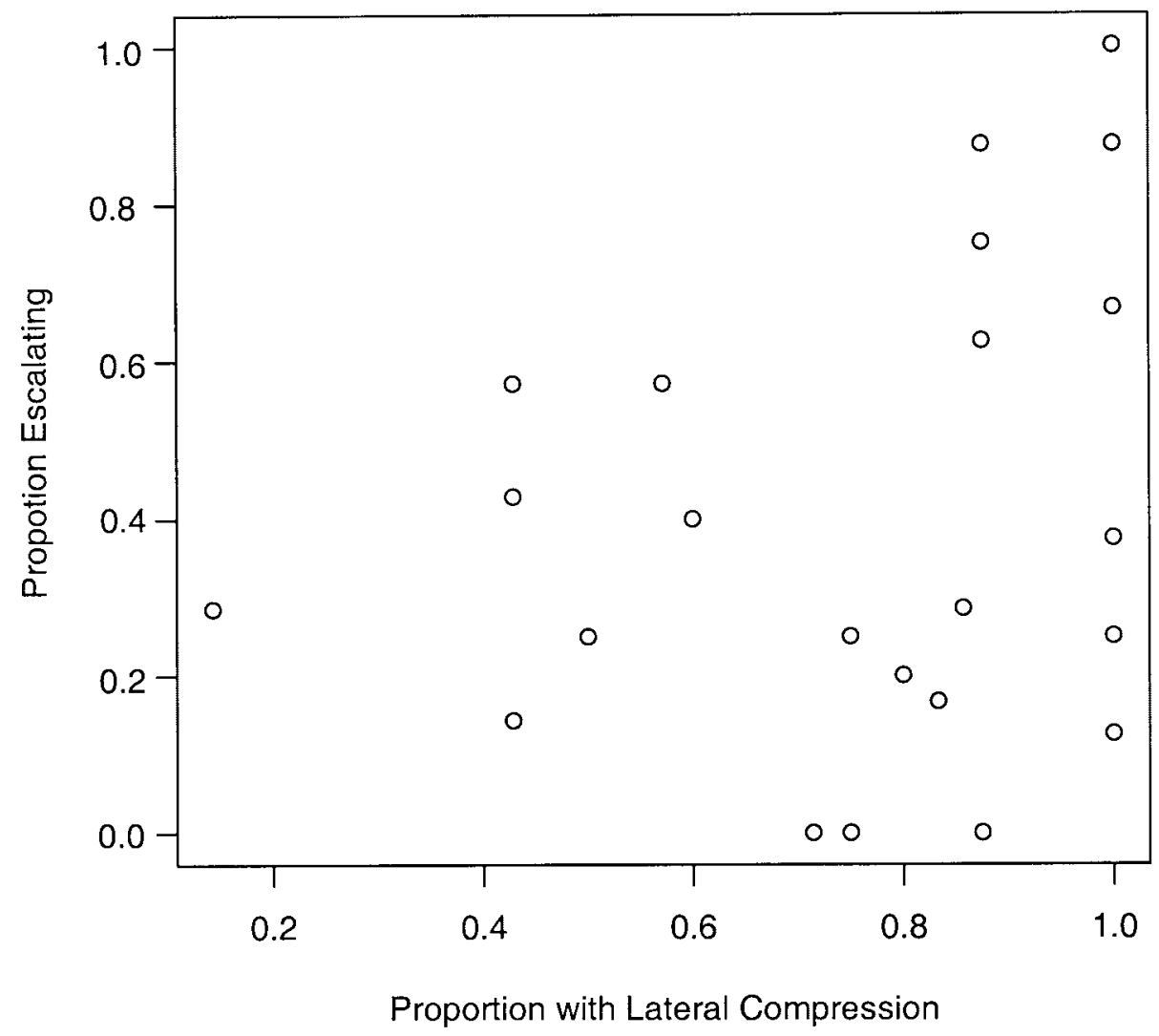

Fig. 8. There was no correlation between the number of trials in which an individual displayed lateral compression and the proportion of trials in which the individual escalated.

six days, four on seven days, and six lizards showed lateral compression on all eight days. Once laterally compressed, lizards tended to remain so for the duration of the test period.

There was no significant difference in the probability of a lizard escalating as a function of whether or not it acquired lateral compression $\left(\chi_{2}^{2}=1.49, \mathrm{p}=0.22\right.$, Table II). There was no correlation between the proportion of trials in which a specific individual escalated and the proportion in which it was laterally compressed $(\mathrm{r}=0.16, \mathrm{p}=0.43$, $\mathrm{N}=26$, Fig. 8; cases in which there was no aggressive behaviour at all were dropped from the analysis). 
Table III. Morphological Correlates of Threat Display Use

\begin{tabular}{|c|c|c|c|c|c|}
\hline \multirow[b]{2}{*}{ Signal } & \multicolumn{2}{|c|}{ Mass } & \multicolumn{2}{|c|}{ Condition } & \multirow[b]{2}{*}{$\mathrm{df}$} \\
\hline & $r_{s}$ & $p$ & $\mathrm{r}_{\mathrm{s}}$ & $p$ & \\
\hline Headbobs & 0.21 & 0.28 & 0.14 & 0.47 & 25 \\
\hline Pushups & 0.05 & 0.79 & 0.13 & 0.53 & 25 \\
\hline \multicolumn{6}{|l|}{ Four Leg } \\
\hline Pushups & -0.16 & 0.42 & -0.17 & 0.39 & 25 \\
\hline \multicolumn{6}{|l|}{ Proportion } \\
\hline Pushups & -0.29 & 0.17 & 0.01 & 0.95 & 23 \\
\hline \multicolumn{6}{|l|}{ Proportion } \\
\hline Four Leg & -0.25 & 0.22 & -0.28 & 0.17 & 23 \\
\hline \multicolumn{6}{|l|}{ Pushups } \\
\hline \multicolumn{6}{|l|}{ Laterally } \\
\hline Compressed & 0.14 & 0.47 & 0.17 & 0.39 & 25 \\
\hline Headbobs & & & & & \\
\hline \multicolumn{6}{|l|}{ Laterally } \\
\hline Compressed & 0.08 & 0.69 & 0.18 & 0.36 & 25 \\
\hline \multicolumn{6}{|l|}{ Pushups } \\
\hline \multicolumn{6}{|l|}{ Type A \& B } \\
\hline Headbobs & 0.30 & 0.13 & -.01 & 0.97 & 25 \\
\hline \multicolumn{6}{|l|}{ Proportion } \\
\hline Type A \& B & 0.33 & 0.11 & -.04 & 0.83 & 25 \\
\hline Headbobs & & & & & \\
\hline
\end{tabular}

\section{Mass, Condition, and Display}

There was no significant correlation between Mass and Condition and the number of headbobs, pushups or headbobs and pushups performed when laterally compressed (Table III). There was a non-significant trend towards heavier lizards (but not those in better condition) to use a higher proportion of type A and B headbobs.

\section{DISCUSSION}

Headbob type (rhythm A, B, or C) provides information about impending escalation; most headbobs used were type $\mathrm{C}$, except immediately prior to escalation when types $\mathrm{A}$ and $\mathrm{B}$ predominated. Pushing up and lateral compression did not provide information about impending escalation. The proportion of four-legged pushups was associated with escalation, but lizards that escalated (charged or attacked) did not differ in the use of four-legged pushups until the seventh headbob. An average of 5.7 headbobs preceded the first charge or attack, suggesting that this difference in four-legged pushups is due to a lower proportion of pushups performed after escalation [or at closer ranges, DeCourcy and Jenssen, 1994; Jenssen, 1977] rather than signalling of impending escalation. Lateral compression did not signal impending 
escalation, and was not correlated with condition. There was sufficient variation in condition to allow for condition effects to be detected, had they been present. While every attempt was made to keep each lizard as healthy as possible, there was quite a range of condition in the lizards used. Fat reserves, indexed according to bone definition around the pelvis, was more variable in the lizards at time of testing than in lizards caught in the field.

The function of lateral compression is probably to increase the saggital profile, perhaps as an amplifier [Hasson, 1989, 1990; Taylor et al., 2000] allowing for more accurate assessment of body size.

The known relationship between inter-male range and headbob type does not seem to account for headbob type results. DeCourcy and Jenssen [1994] found only a subtle effect of range upon headbob type between the long $(>60 \mathrm{~cm})$ and medium $(20-60 \mathrm{~cm})$ ranges [Fig. 6 in DeCourcy and Jenssen, 1994]), whereas the bulk of variation in headbob choice attributable to range was between the short $(<20 \mathrm{~cm})$ and medium ranges. While no explicit measurements of distance to the mirror were taken, few, if any, headbobs that preceded an advance were performed at less than $10 \mathrm{~cm}$ from the mirror [corresponding to the "short" range in DeCourcy and Jenssen, 1994]. The vast majority of the headbobs prior to advance will be in the range of 50-75 cm. Furthermore, an internal control exists for distance; the present results compare headbobs leading up to an advance to the last headbob before advancing. DeCourcy and Jenssen [1994] found that type C accounted for about $70 \%$ of long-range bobs, $60 \%$ of medium range, and $25 \%$ of short range bobs. One-quarter of short range bobs cannot be dismissed as an insignificant number. It is unlikely that these lizards are using headbob type to signal range. It is more likely that lizards at different ranges are signalling different intensities of threat.

In order for threat displays to be evolutionarily stable, they must impart some information, even if it is imprecise, about the signaller's fighting ability, level of motivation, or aggressiveness. If receivers interpret more pushups, more compression, or more $\mathrm{A}$ and $\mathrm{B}$ headbobs as increasingly threatening, then at least some signallers must follow this rule. It cannot be an ESS for increased threat display to always be a "bluff" because increased display would then indicate a lower probability of impending attack.

It is difficult to estimate the actual energy costs of specific threat displays. Physiological costs of all aggressive behaviours can be measured. For instance, male mountain spiny lizards, Sceloporus jarrovi, treated with testosterone implants, show a long-term $31 \%$ increase in energy expenditure for a 3.5 fold increase in territorial aggression [Marler et al., 1995]. Estimating the physiological costs of displays, however, is more difficult. Brandt (unpublished observations) found that a five-minute mirror image presentation lead to an average $15 \%$ increase in blood lactate levels, and an average $11 \%$ decrease in treadmill endurance (19 of 26 lizards showed decreased endurance after the mirror presentation). There are no data describing attempts to measure the physiological cost of different specific displays within a species, or variations between displays, such as the different rhythms of headbobs, or the number of legs used to pushup during a headbob. It is this difference in costs between alternative signals, rather than the overall cost of aggression, or the cost of using threat displays per se that is relevant to theory.

Encounters observed in this study, and others like it are staged, and will be more escalated than the majority of agonistic encounters in the field. An investigation into the significance of alternative agonistic display choice must examine fairly escalated contests, in which a more complete range of displays are used, and there is a significant risk of physical fighting. Less escalated encounters, in which there is no real risk of physical contact, will use a greatly restricted repertoire of threats, and have little chance of detecting socially mediated costs. 
Staging interactions is required in order to sample a sufficient number of relatively escalated contests. The behaviour seen in this study was not significantly different from that seen in other studies. Lizards displaying to a live opponent perform $2.4 \pm 0.21$ headbobs per minute [DeCourcy and Jenssen, 1994]. Individual averages toward the mirror image during the 5min. periods analyzed in this study were $1.3 \pm 1.3$ headbobs per minute.

Staging encounters between two lizards introduces an interaction confound in which it is impossible to separate one individual's behaviour from the effect of the opponent. Agonistic behaviour among green anoles has been shown to be extremely sensitive to the opponent's actions [McMann, 1993]. Presentation of a mirror image controls for this and ensures that each act of escalation is internal to the animal, rather than being a reaction to possible escalation by the opponent.

Display use can be expected to correlate with absolute size, either because it signals fighting ability directly, or because larger lizards, those more likely to prevail in the subsequent fight, are less conservative in using displays that may elicit counter-attack [Adams and MestertonGibbons, 1995; Hurd, 1997]. Investigations teasing apart intrinsic variation in aggressive behaviour must control for opponent size and tendency to escalate. Mirror image stimulation also controls for size effects, for each lizard is perfectly size-matched to its opponent. Fight outcome in Anolis is strongly associated with size asymmetry; larger lizards are significantly more likely to defeat their opponents [Hurd, unpublished observations; Tokarz, 1985]. Size asymmetry is not assessed perfectly or instantaneously however, and information about size asymmetry is gained gradually [Brick, 1999; Englund and Olsson, 1990; Englund and Otto, 1991; Enquist and Jakobsson, 1986; Enquist et al., 1987, 1990; Keeley and Grant, 1993; Koops and Grant, 1993; Leimar et al., 1991]. This allows a role for aggressive communication of fighting ability. If opponents were able to perfectly and instantaneously assess each other's of size, a great many threat displays would be superfluous [Enquist and Leimar, 1983, 1987; Leimar and Enquist, 1984]. Display use can be analyzed as a function of absolute size, when relative size asymmetry effects would greatly complicate the interpretation of the data.

There has been some concern over the use of mirror image stimuli in studies of aggressive behaviour, due to the discrepancy between indices of mirror-elicited behaviour and dominance hierarchies, as measured through subsequent staged interactions [Ruzzante, 1992]. This concern is based upon the assumption that dominance, fighting ability, and aggressiveness (defined as individual variation in tendency to escalate a contest given a constant perceived value of winning) are the same thing. Fight outcome in Anolis is determined by size asymmetry [Tokarz, 1985, Hurd, unpublished observations]. There is some evidence to suggest that there is persistent variation in aggressiveness scores in these animals, uncorrelated with size [Hurd, unpublished data]. There is widespread agreement that mirror image testing is an acceptable technique for measuring aggressiveness [Holtby and Swain, 1992; Ruzzante, 1992; Hamilton and Poulin, 1995], and scores have been shown to correlate well with the same measures against live opponents [Holtby et al., 1993; Swain and Holtby, 1989; Swain and Riddell, 1990]. Mirror image stimulation has been employed to good effect using Anolis carolinensis in previous experiments [Baxter and Ackermann, 1997; Korzan et al., 2000a,b, 2002].

In conclusion, the data presented support the conventional signalling hypothesis, The most informative signal is the least likely to be a handicap. Headbob types are almost certainly conventional signals, and provide information about impending attack. Pushup type and lateral compression remain possible handicaps, but they provide no information about impending attack, fighting ability, or condition. Scepticism not withstanding [e.g. Deag and 
Scott, 1999; Taylor et al., 2000; Zahavi, 1993], the existence of conventional threat displays has long been supported by theory [Enquist, 1985; Enquist et al., 1998; Hurd, 1997; Hurd and Enquist, 1998], though very little empirical work [e.g., Molles and Vehrencamp, 2001; Vehrencamp, 2001] has supported their existence.

A conclusive test of conventional signalling models will require a controlled presentation of alternative signals, through physical or computer generated models. Increasing levels of conventional threat should elicit a greater degree of escalation from a smaller proportion of the opponent population, those with higher RHP or motivation.

\section{ACKNOWLEDGEMENTS}

This work was partially funded by an NSERC Canada post-doctoral fellowship to the author, and an operating grant to Michael J. Ryan. The author wishes to thank Tom Jenssen, Judy Stamps, Mike Ryan, and David Crews for valuable discussions and comments on earlier versions of this manuscript. Yoni Brandt, David Crews, Kelly Farley, Monica Garrison, Cindy Gill, Nikhil Mane, Charla Mathews, Kate LeVering, Gad Perry, and Mike Singer provided essential resources and assistance. Yoni Brandt's unpublished observations were presented as a poster at the 1998 International Society for Behavioural Ecology meeting.

\section{REFERENCES}

Adams ES, Mesterton-Gibbons M. 1995. The cost of threat displays and the stability of deceptive communication. J Theor Biol 175:405-421.

Alcock J. 1998. Animal behavior. 6th ed. Sinauer. Baxter LR, Ackermann RF. 1997. Specific brain circuit activation and 5-HT function during ritualistic territorial display vs. non-display in the anole lizard. Soc Neurosci Abs 23:744.

Brandt Y. 2003. Lizard threat display handicaps endurance. Proc Roy Soc Lond B 270:1061-1068.

Brick O. 1999. A test of the sequential assessment game: the effect of increased cost of sampling. Behav Ecol 10:726-732.

Caryl PG. 1979. Communication by agonistic displays: what can games theory contribute to ethology? Behaviour 68:136-169.

Dawkins R, Krebs JR. 1978. Animal signals: information or manipulation? In: Krebs JR, Davies NB, editors, Behavioural Ecology: an evolutionary approach, 1st ed., pp. 282-309. Oxford: Blackwell.

Deag JM, Scott GW. 1999. "Conventional" signals in avian agonistic displays: integrating theory, data and different levels of analysis. J Theor Biol 196:155-162.

Deckel AW. 1995. Laterality of aggressive responses in Anolis. J Exp Zool 272:194-200.

DeCourcy KR, Jenssen TA. 1994. Structure and use of male territorial headbob signals by the lizard Anolis carolinensis. Anim Behav 47:251-262.
Englund G, Olsson TI. 1990. Fighting and assessment in the net-spinning caddis larva Arctopsyche ladogensis: a test of the sequential assessment game. Anim Behav 39:55-62.

Englund G, Otto C. 1991. Effects of ownership statue, weight asymmetry, and case fit on the outcome of case contests in two populations of Agrypnia pagetana (Trichoptera: Phryganeidae) larvae. Behav Ecol Sociobiol 29:113-120.

Enquist M. 1985. Communication during aggressive interactions with particular reference to variation in choice of behaviour. Anim Behav 33:1152-1161.

Enquist M, Jakobsson S. 1986. Decision making and assessment in the fighting behaviour of Nannacara anomala (Cichlidae, Pisces). Ethology 72:143-153.

Enquist M, Leimar O. 1983. Evolution of fighting behaviour: decision rules and assessment of relative strength. J Theor Biol 102:387-410.

Enquist M, Leimar O. 1987. Evolution of fighting behaviour: the effect of variation in resource value. J theor Biol 127:187-205.

Enquist M, Ljungberg T, Zandor A. 1987. Visual assessment of fighting ability in the cichlid fish Nannacara anomala. Anim Behav 35:1262-1264.

Enquist M, Leimar O, Ljungberg $\mathrm{T}$, Mallner $\mathrm{Y}$, Segerdahl N. 1990. A test of the sequential assessment game: fighting in the cichlid fish Nannacara anomala. Anim Behav 40:1-14. 
Enquist M, Ghirlanda S, Hurd PL. 1998. Discrete conventional signalling of continuously varying resource value. Anim Behav 56:749-753.

Gerhardt HC. 1994. The evolution of vocalization in frogs and toads. Ann Rev Ecol Syst 25:293-324.

Grafen A. 1990. Biological signals as handicaps. J theor Biol 144:517-546.

Greenberg N. 1977. A neuroethological study of display behavior in the lizard Anolis carolinensis (Reptilia, Lacertilia, Iguanidae. Amer Zool 17:!191-201.

Hamilton WJ, Poulin R. 1995. Parasites, aggression, and dominance in male upland bullies. J Fish Biol 47:302-307.

Hasson O. 1989. Amplifiers and the handicap principle in sexual selection: a different emphasis. Proc R Soc Lond B 235:383-406.

Hasson O. 1990. The role of amplifiers in sexual selection: an integration of the amplifying and the Fisherian mechanisms. Evol Ecol 4:277-289.

Holtby LB, Swain DP. 1992. Through a glass, darkly: a response to Ruzzante's reappraisal of mirror imnage stimulation studies. Can J Fish Aquat Sci 49:1968-1969.

Holtby LB, Swain DP, Allen GM. 1993. Mirror-elicited agonistic behaviour and body morphology as predictors of dominance status in juvinile Coho Salmon (Oncorhynchus kisutch). Can J Fish Aquat Sci 50:676-684.

Hurd PL. 1997. Is signalling of fighting ability costlier for weaker individuals? J Theor Biol 184:83-88.

Hurd PL, Enquist M. 1998. Conventional signalling in aggressive interactions: the importance of temporal structure. J Theor Biol 192:197-211.

Hurd PL, Enquist PL. 2001. Threat display in birds. Can J Zool 79:931-942.

Ihaka R, Gentleman R. 1996. R: A Language for Data Analysis and Graphics. J Comp Graph Stats 5:299-314.

Jenssen TA. 1977. The evolution of anoline lizard display behavior. Amer Zool 17:203-215.

Jenssen TA, Orrell KS, Lovern MB. 2000. Sexual dimorphisms in aggressive signal structure and use by a polygynous lizard, Anolis carolinensis. Copeia 2000:140-149.

Johnstone RA. 1997. The evolution of animal signals. In: Behavioural Ecology: an evolutionary approach, 4th ed., pp. 155-178. Blackwell. Johnstone RA. 1998. Game theory and communication. In: Dugatkin LA, Reeve HK, editors, Game theory and animal Behavior, pp. 64-93. Oxford.

Keeley ER, Grant JWA. 1993. Visual information, resource value, and sequential assessment in convict cichlid (Cichlasoma nigrofasciatum) contests. Behav Ecol 4:345-349.

Kim YG. 1995. Status signalling games in animal contests. J theor Biol 176:221-231.
Koops MA, Grant JWA. 1993. Weight asymmetry and sequential assessment in convict cichlid contests. Can J Zool 71:475-479.

Korzan WJ, Summers TR, Ronan PJ, Summers CH. 2000a. Visible sympathetic activity as a social signal in Anolis carolinensis: changes in aggression and plasma catecholamines. Horm Behav 38:193-199.

Korzan WJ, Summers TR, Summers CH. 2000b. Monoaminergic activities of limbic regions are elevated during aggression: influence of sympathetic social signaling. Brain Res 870:170-178.

Korzan WJ, Summers TR, Summers CH. 2002. Manipulation of visual sympathetic sign stimulus modifies social status and plasma catecholamines. Gen Comp Endocinol 128:153-161.

Krebs JR, Dawkins R. 1984. Animal signals: mindreading and manipulation. In: Behavioural Ecology: an evolutionary approach, 2nd ed., pp. 380-402. Sinauer. Leimar O, Enquist M. 1984. The effects of asymmetries in owner-intruder interactions. $\mathbf{J}$ theor Biol 111:475-491.

Leimar O, Austad S, Enquist M. 1991. A test of the sequential assessment game: fighting in the bowl and doily spider Frontinella pyramitela. Evolution 45:862-874.

Marler CA, Walsberg G, White ML, Moore M. 1995. Increased energy expenditure due to increased territorial defense in male lizards after phenotypic manipulation. Behav Ecol Sociobiol 37:225-231.

Martins EP. 1993. Contextual use of the push-up display by the sagebrush lizard, Sceloporus graciosus. Anim Behav 45:25-36.

Maynard Smith J. 1974. Theory of games and the evolution of animal contests. J theor Biol 47:209-221.

McMann S. 1993. Contextual signalling and the structure of dyadic encounters in Anolis carolinensis. Anim Behav 46:657-668.

Molles LE, Vehrencamp SL. 2001. Songbird cheaters pay a retaliation cost: evidence for auditory conventional signals. Proc Roy Soc Lond B 268:2013-2019.

Riechert SE. 1998. Game theory and animal contests. In: Dugatkin LA, Reeve HK, Editors. Game theory and animal Behavior, pp. 64-93. Oxford.

Ruzzante DE. 1992. Mirror image stimulation, social hierarchies, and population differences in agonistic behaviour: a reappraisal. Can J Fish Aquat Sci 49:1966-1968.

Swain DP, Holtby LB. 1989. Differences in morphology and behavior between juvinile Coho Salmon (Oncorhynchus kisutch) rearing in a lake and its tributary stream. Can J Fish Aquat Sci 46:1406-1414.

Swain DP, Riddell BE. 1990. Variation in agonistic behaviour between newly emerged juviniles from hatchery and wild populations of Coho 
Salmon, Oncorhynchus kisutch. Can J Fish Aquat Sci 47:566-571.

Taylor PW, Hasson O, Clark DL. 2000. Body condition and patterns as amplifiers of physical condition. Proc Roy Soc Lond B 267:917-922.

Tokarz RR. 1985. Body size as a factor determining dominance in staged agonistic encounters between male brown anoles (Anolis sagrei). Anim Behav 33:746-753.

Vehrencamp SL. 2001. Is song-type matching a conventional signal of aggressive intentions? Proc Roy Soc Lond B 268:1637-1642.

Zahavi A. 1993. The fallacy of conventional signalling. Phil Trans R Soc Lond B 340:227-230. 